\title{
M2b Macrophage Elimination and Improved Resistance of Mice with Chronic Alcohol Consumption to Opportunistic Infections
}

\author{
Hideko Ohama, ${ }^{*}$ Akira Asai, ${ }^{*}$ Ichiaki Ito, ${ }^{\dagger}$ Sumihiro Suzuki, ${ }^{\dagger}$ Makiko Kobayashi, ${ }^{\dagger}$ Kazuhide Higuchi, ${ }^{*}$ and Fujio Suzuki
}

From the Second Department of Internal Medicine, * Osaka Medical College, Takatsuki, Japan; the Department of Internal Medicine, ${ }^{\dagger}$ The University of Texas Medical Branch, Galveston, Texas; and the Department of Biostatistics and Epidemiology, ${ }^{\ddagger}$ University of North Texas Health Science Center, Fort Worth, Texas

Accepted for publication September 30, 2014.

Address correspondence to Fujio Suzuki, Ph.D., The University of Texas Medical Branch, Department of Internal Medicine, 301 University Blvd., Galveston, TX 77555-0435. E-mail: fsuzuki@utmb.edu.

\begin{abstract}
Alcohol abuse was found to predispose persons to opportunistic infections. In this study, we tried to improve the host antibacterial resistance of chronic alcohol-consuming (CAC) mice to opportunistic infections. Bactericidal macrophages with functions to produce IL-12 and to express mRNAs for CXCL9 and inducible nitric oxide synthase (M1 macrophages) were characterized as the main effector cells in host antibacterial innate immunities against infections with opportunistic pathogens. However, CAC mice were found to be carriers of M2b macrophages [macrophages with functions to produce IL-10 and to express mRNAs for CD163, chemokine ligand (CCL)1, and LIGHT (homologous to lymphotoxin, exhibits inducible expression, competes with herpes simplex virus glycoprotein $D$ for high-voltage electron microscopy on T cells)], which were inhibitory on macrophage conversion from resident macrophages to M1 macrophages. Under treatment with CCL1 antisense oligodeoxynucleotides, a specific inhibitor of $\mathrm{M} 2 \mathrm{~b}$ macrophages, CAC mouse macrophages reverted to resident macrophages, and M1 macrophages were induced by a bacterial antigen from macrophages of CAC mice that were previously treated with the oligodeoxynucleotides. Opportunistic infections (enterococcal translocation and Klebsiella pneumonia) in CAC mice were completely controlled by CCL1 antisense oligodeoxynucleotides. These results indicate that certain opportunistic infections in alcoholics are controllable through the modulation of M2b macrophages. (Am J Pathol 2015, 185: 420-431; http://dx.doi.org/ 10.1016/j.ajpath.2014.09.022)
\end{abstract}

Alcohol abuse is the third-leading preventable cause of death in the United States, resulting in approximately 100,000 deaths each year. In addition, alcohol abuse causes enormous economic burden. ${ }^{1}$ Epidemiologic and clinical studies have found that alcohol abuse predisposes persons to opportunistic infections. $^{2-5}$ The most common alcohol-related bacterial infections include i) pneumonia because of infection with Streptococcus pneumoniae, Klebsiella pneumoniae, Staphylococcus aureus, Haemophilus influenza, Legionella pneumoniae, and Mycobacterium tuberculosis ${ }^{4-7}$; ii) bacterial meningitis because of infection with $S$. pneumoniae and Listeria monocytogenes ${ }^{8}$; and iii) bacterial translocation from gastrointestinal tracts because of the overgrowth of bacteria in the small intestine, mucosal barrier deficiency, and impaired immune defense mechanisms. ${ }^{9,10}$ Antibiotics are commonly used against these opportunistic infections. In the case of gut-bacterial infections, however, antibiotic chemotherapies often result in abnormal microflora and multiple antibioticresistant bacterial generation because of the long treatment duration and large doses of the antibiotics commonly prescribed in these patients. In addition, oral antibiotic treatment frequently causes overgrowth of commensal fungi in the gut and increases plasma concentration of prostaglandin $\mathrm{E}_{2}$, which induces immunosuppression. ${ }^{11}$ Thus, continued development of new paradigms to treat infections associated with alcohol abuse is necessary. Because most of the causative pathogens of infections related to alcohol abuse are endogenous flora and because severe infections with

Supported by The University of Texas Medical Branch account Education, Research and Development (F.S.).

Disclosures: None declared. 
these pathogens are not developed in healthy persons, ${ }^{2-10}$ some immune dysfunctions related to alcohol abuse are the underlying reasons for the increased susceptibility of alcoholics to infections. From these facts, we have hypothesized that certain infections associated with alcohol abuse are immunologically controllable.

Host antibacterial immune functions are strongly influenced by chronic alcohol consumption. ${ }^{11-27}$ Observed signs of decreased immune functions include granulopoiesis ${ }^{13}$; tissue recruitment of neutrophils, ${ }^{14}$ phagocytosis, ${ }^{14-17}$ and Toll-like receptor responses of macrophages ${ }^{18}$; and expression and production of type 1 helper T cell (Th1) responses. ${ }^{19}$ Decreased macrophage phagocytosis ${ }^{16,17}$ and increased Th2 responses ${ }^{19-21}$ were found in the intestinal mucosa of alcoholics. A decrease in the antigen-presenting abilities of dendritic cells, ${ }^{22}$ perforin/granzyme expression, and interferon- $\gamma$ production by innate lymphoid cells ${ }^{23,24}$ and Th1 and Th17 responses $^{25-27}$ were reported in alcoholics. All of these facts were suggested as factors in the increased susceptibility of alcoholics to opportunistic infections. However, it is still unclear how host antibacterial resistance against various types of opportunistic infections is influenced by these immune dysfunctions.

The innate immune system is the first line of host defense against invading pathogens. ${ }^{28}$ In healthy persons, opportunistic pathogens are usually eliminated at the local infection site by host antibacterial innate immune responses. Macrophages, neutrophils, innate lymphoid cells, dendritic cells, and antimicrobial peptides produced by dermal and intestinal epithelial cells are described as effector cells or factors, of innate immune responses. M1 macrophages are known as main effector cells in host antibacterial innate immunities. $^{29-33}$ However, M1 macrophages were not easily generated in patients whose M2 macrophages predominated. ${ }^{34}$ M2 macrophages inhibit macrophage conversion from resident macrophages to M1 macrophages. ${ }^{35}$ Therefore, hosts who are carriers of M2 macrophages are more susceptible to various opportunistic infections. So far, four different M2 macrophages have been observed: M2a, M2b, M2c, and M2d macrophages. ${ }^{36-39}$ Each subtype of M2 macrophages is discriminated by their surface antigen expression and cytokine/chemokine-producing profiles. All subtypes of M2 macrophages are equally immunosuppressive. M2d macrophages were observed in tumor-growing sites and accelerate the tumor growth. ${ }^{39}$

In this study, chronic alcohol-consuming (CAC) mice were found to be susceptible to opportunistic infections, and a predominance of M2 macrophages was found in these mice. M2b macrophages isolated from 12-week CAC mice (mice consuming $0.5 \mathrm{~mL}$ of $20 \%$ ethanol for 12 weeks) reverted to resident macrophages after treatment with chemokine ligand (CCL) 1 antisense oligodeoxynucleotides (ODNs). CCL1 is known as an essential chemokine for the maintenance of M2b macrophage properties. Subsequently, M1 macrophages, main effector cells on the host antibacterial resistance, were induced by a bacterial antigen in 12-week
CAC mice previously treated with CCL1 antisense ODNs. Enterococcal translocation and Klebsiella pneumonia were not detected in CAC mice depleted of M2b macrophages. These results indicate that certain opportunistic infections in alcoholics are controllable if M2b macrophages, appearing in response to chronic alcohol consumption, can be modulated. CCL1 antisense ODNs are found to be a beneficial weapon for modulating $\mathrm{M} 2 \mathrm{~b}$ macrophage properties in CAC mice.

\section{Materials and Methods}

\section{Mice}

Nine- to 12-week-old pathogen-free male BALB/c mice, severe combined immunodeficient (SCID) mice, SCIDbeige (SCIDbg) mice, nonobese diabetic (NOD)/scid mice, and NOD/scid IL-2R $\gamma^{\text {null }}$ (NSG) mice were purchased from The Jackson Laboratory (Bar Harbor, ME). SCID mice and NOD/scid mice do not have functional $\mathrm{T}$ and $\mathrm{B}$ cells, and SCIDbg mice are SCID mice without natural killer (NK) cells. SCIDbgM mice are SCIDbg mice depleted of macrophages, SCIDbgN mice are SCIDbg mice depleted of neutrophils, and SCIDbgNM mice are SCIDbg mice depleted of macrophages and neutrophils. Neutrophils were depleted from SCIDbg mice by wholebody $\gamma$-irradiation (4 Gy; 2 days before cell inoculation; SCIDbgN mice). ${ }^{40}$ When bone marrow cells or peripheral blood cells taken from SCIDbgN mice were tested morphologically for residual neutrophils after WrightGiemsa and alkaline phosphatase staining, neutrophils were not detected until 7 days after the irradiation. ${ }^{40}$ Macrophages were depleted from SCIDbg mice by treatment with $5 \mathrm{mg} / \mathrm{kg}$ gadolinium chloride (i.v.; 24 hours before cell inoculation; SCIDbgM mice). ${ }^{41}$ To deplete both macrophages and neutrophils, SCIDbg mice treated with gadolinium chloride were exposed to whole-body $\gamma$-irradiation. SCIDbgMN mice were defined as mice without functional T cells, B cells, NK cells, neutrophils, and macrophages. NSG mice were found to be without functional T cells, B cells, and NK cells. ${ }^{42-45}$ In addition, NSG mice are carriers of macrophages with defective functions (phagocytosis, digestion, antigen presentation, and activation). ${ }^{42-45}$

\section{Chronic Exposure to Ethanol}

Ethanol $(95 \% \mathrm{v} / \mathrm{v})$ was diluted to $20 \%(\mathrm{v} / \mathrm{v})$ with physiologic saline. CAC mice were prepared by oral gavage of $0.5 \mathrm{~mL}$ of $20 \%$ ethanol $(0.1 \mathrm{~g} / \mathrm{d})$ for 4 to 16 weeks. Control mice received saline in the same fashion. Serum aspartate transaminase and alanine aminotransferase concentrations significantly increased in mice consuming ethanol for 12 weeks compared with concentrations in control mice. However, these concentrations did not increase in mice consuming ethanol for 4 weeks. In addition, the ratio of 
serum aspartate transaminase to alanine aminotransferase was increased in mice consuming ethanol for 12 weeks, whereas the ratio in mice consuming ethanol for 4 weeks was not different from that of normal mice. The Institutional Animal Care and Use Committee of The University of Texas Medical Branch at Galveston approved all procedures that used animals (approval number 1204024).

\section{Bacteria, Reagents, and Media}

Enterococcus faecalis (29212 strain) and K. pneumoniae (43816 strain) were purchased from ATCC (Manassas, VA). Before being used in these experiments, E. faecalis and $K$. pneumoniae were cultured in tryptic soy broth for 16 hours at $37^{\circ} \mathrm{C}$. The cultures were centrifuged at $2000 \times g$ for 15 minutes, and the bacterial pellet was suspended in phosphate-buffered saline (PBS). The number of bacteria in the suspension were counted with a hemocytometer and adjusted to give the approximate desired inocula. The inocula were verified by serial 10 -fold dilutions of the bacterial suspensions and plated on tryptic soy agar or brainheart infusion agar. Recombinant (r)IL-10, rIL-12, rCCL1, rCCL17, and rCXCL13 were obtained from PeproTech (San Diego, CA). Monoclonal antibodies for IL-10, IL-12, CCL1, CCL17, and CXCL13 were obtained from R\&D Systems (San Diego, CA) and BD Biosciences (San Jose, CA). Streptavidin particles plus-DM and IMag buffer were purchased from BD Biosciences. Biotin-conjugated antimouse F4/80 monoclonal antibody was obtained from eBioscience (San Diego, CA). Gadolinium chloride was obtained from Aldrich Chemical Co. (Milwaukee, WI). Heat-killed E. faecalis and K. pneumoniae were prepared by heating bacteria at $65^{\circ} \mathrm{C}$ for 30 minutes. The inactivated properties of these cells were confirmed by culturing them on agar plates. Heat-killed bacteria were stored at $-80^{\circ} \mathrm{C}$ until needed. For cultivation of macrophages, RPMI-1640 medium supplemented with $10 \%$ heat-inactivated fetal bovine serum, $2 \mathrm{mmol} / \mathrm{L}$ L-glutamine, $100 \mathrm{U} / \mathrm{mL}$ penicillin, and $100 \mu \mathrm{g} / \mathrm{mL}$ streptomycin (complete medium) was used.

\section{Preparation of Macrophages}

Macrophages were prepared from mesenteric lymph nodes (MLNs) of normal and CAC mice. Single cells, obtained by gently pressing MLNs through a cell strainer, were adjusted to $5 \times 10^{6}$ cells $/ \mathrm{mL}$ in MagCellect buffer (R\&D Systems). Macrophages were isolated from these cell suspensions by a positive selection technique that used magnetic beads coated with anti-F4/80 monoclonal antibody. Purified $\mathrm{F} 4 / 80^{+}$cells ( $>98 \%$ viable and $>97 \%$ pure as $\mathrm{F} 4 / 80^{+}$cells) were consistently obtained by this procedure.

Macrophages were also isolated from bronchoalveolar lavage fluids of normal and 12-week CAC mice. Cells from bronchoalveolar lavage fluids were obtained from the lungs by extensive washing with PBS. CD68 ${ }^{+}$cells were purified from these cell preparations by using magnetic beads coated with
anti-CD68 monoclonal antibody, as described in the previous paragraph. These macrophages were used to determine antibacterial functions in vivo (NSG mice) and in vitro (bactericidal activity) against infections with $K$. pneumoniae.

\section{Characterizations of Macrophages}

MLN F4/80 cells $\left(1 \times 10^{6}\right.$ cells $\left./ \mathrm{mL}\right)$ from CAC mice or normal mice were stimulated with heat-killed E. faecalis $\left(10^{6}\right.$ cells $\left./ \mathrm{mL}\right)$ for 12 to 48 hours. Culture fluids harvested were assayed for IL-12 (p35/p40 heterodimer), IL-10, CCL17, CCL1, and CXCL13, and cells obtained were tested for the expression of various mRNAs by RT-PCR. The following mRNAs were included: CXCL9, inducible nitric oxide synthase (iNOS), CD163, mannose receptor, ARG1, Chu313/Ym1, LIGHT (homologous to lymphotoxin, exhibits inducible expression, competes with herpes simplex virus glycoprotein $\mathrm{D}$ for high-voltage electron microscopy on $\mathrm{T}$ cells), vascular endothelial growth factor, and CCL1. In addition, the same cells were analyzed for surface expression of CD163 and intracellular IL-10 and IL-12 by using FACSCanto flow cytometer. Macrophages with functions to produce IL-12 and to express mRNAs for CXCL9 and inducible nitric oxide synthase were identified as M1 macrophages. Macrophages with functions to produce IL-10 and CCL17 and to express mRNAs for CD163, mannose receptor, ARG1, or Chu313/Ym1 were identified as M2a macrophages. ${ }^{35-37}$ Macrophages with functions to produce IL-10 and to express mRNAs for CD163, LIGHT, and CCL1 were identified as M2b macrophages. ${ }^{37}$ Macrophages with functions to produce IL-10 and CXCL13 and to express mRNAs for CD163, mannose receptor, ARG1, or Chu313/Ym1 were identified as M2c macrophages. ${ }^{35-37}$ Macrophages with functions to produce IL-10 and to express mRNAs for CD163 and vascular endothelial growth factor were considered to be M2d macrophages. ${ }^{39}$

\section{Bactericidal Activity of Macrophages}

Macrophages $\left(1 \times 10^{6}\right.$ cells $\left./ \mathrm{mL}\right)$ from MLNs or alveolar lavages of normal mice were suspended in antibiotic-free RPMI-1640 media supplemented with $10 \%$ fetal bovine serum. These cells were then stimulated for 24 hours with $10^{6}$ cells $/ \mathrm{mL}$ of the bacterial antigens (MLN macrophages, heatkilled E. faecalis, alveolar macrophages, heat-killed $K$. pneumoniae). Macrophages stimulated with the antigens were cultured on Transwell plates for 24 hours with the appropriate macrophage preparations derived from 12-week CAC mice $\left(5 \times 10^{5}\right.$ cells $/ \mathrm{mL}$, upper chamber $)$. After cultivation, macrophages harvested from the lower chamber of the Transwell plates were exposed to $3 \times 10^{5}$ colony-forming unit (CFU) per well of E. faecalis or K. pneumoniae. As a control, each pathogen was incubated alone. After 3 hours of incubation, samples were lyzed in $0.1 \%$ Triton X-100 (Sigma-Aldrich, St. Louis, MO). Serial 10-fold dilutions of 
these fluids were plated on tryptic soy agar. The number of colonies was counted after being incubated for 24 hours at $37^{\circ} \mathrm{C}$. The following formula was applied to the results: $(1-$ test group $\mathrm{CFU} /$ control group CFU $) \times 100$.

\section{Bacterial Infections}

\section{Bacterial Translocation}

Normal mice, 4- to 16-week CAC mice, and various immunocompromised mice inoculated with or without macrophages were used in these experiments. For the stabilization of the oral enterococcal infection, mice were decontaminated and treated with a proton-pump inhibitor. ${ }^{46,47}$ Decontaminated mice were treated with drinking water that contained $4 \mathrm{mg} / \mathrm{mL}$ penicillin, streptomycin, and bacitracin for 4 days. ${ }^{46,47}$ This procedure achieved transitory intestinal decontamination in mice for 7 to 10 days. On the day of the final antibiotic treatment, mice were treated orally with lansoprazole (an acid proton-pump inhibitor; $0.5 \mathrm{mg} / \mathrm{mL}$ ) to stabilize oral infection. ${ }^{46}$ Two days after lansoprazole treatment, these mice were infected orally with $10^{6} \mathrm{CFU}$ (corresponds to $<0.01 \mathrm{LD}_{50}$ in normal mice) of $E$. faecalis per mouse. Because a significant number of bacteria were not detected in MLNs and liver of decontaminated mice, the presence of bacteria in the organs of these mice orally infected with $E$. faecalis was considered as evidence for bacterial translocation.

\section{K. Pneumoniae Pulmonary Infection}

Normal mice, 12-week CAC mice, and NSG mice inoculated with or without macrophages were used in these experiments. Under anesthesia with ketamine and xylazine, the trachea was exposed, and $30 \mu \mathrm{L}$ of bacteria inoculum $\left(10^{3} \mathrm{CFU}\right.$ for CAC mice) was injected via a 26-gauge needle. The skin incision was surgically closed. In our preliminary studies, this dose corresponded to $<0.1 \mathrm{LD}_{50}$ in normal mice.

The severity of infection was evaluated by the growth of the bacteria in various organs (bacterial translocation, MLNs and liver; K. pneumoniae infection, spleen and liver) of the test groups in comparison with bacteria of the control groups. To measure the quantity of bacteria, organ specimens were weighed and disrupted in $2 \mathrm{~mL}$ of PBS by a Bruikman homogenizer. A serial 10-fold dilution of the homogenates was plated onto blood agar plates and incubated for 24 hours at $37^{\circ} \mathrm{C}$. The colonies were counted, and the number of bacteria per gram of organ was determined. To determine the percentage of survival, mice were monitored twice a day for 7 days after infection with the pathogens.

\section{Adoptive Transfer of Macrophages}

Macrophages isolated from MLNs of normal mice or 8 -week or 12-week CAC mice were adjusted to $2 \times 10^{7}$ cells $/ \mathrm{mL}$ with PBS, and $0.25 \mathrm{~mL}$ of the cell mixture was
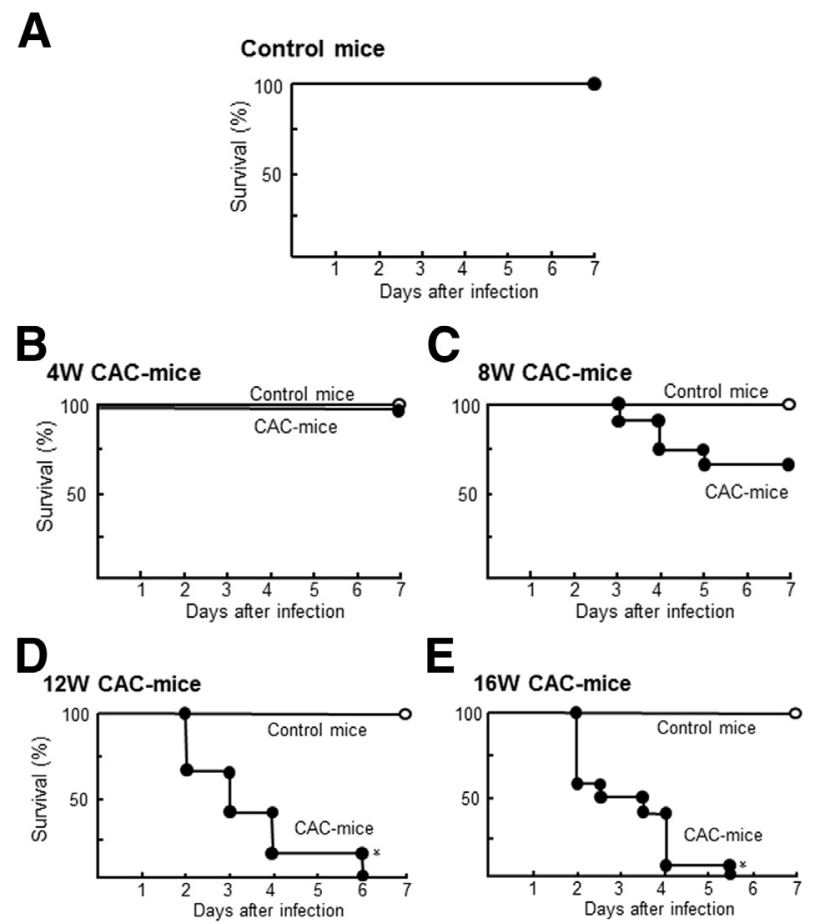

Figure 1 Susceptibility of CAC mice to sepsis that comes from E. faecalis translocation. After decontamination and proton-pump inhibitor treatment, normal mice (A) and mice consuming $20 \%$ ethanol for 4 (B), 8 (C), 12 (D), or 16 (E) weeks were infected orally with $10^{6} \mathrm{CFU}$ of $E$. faecalis per mouse. As controls, mice consuming saline $(0.2 \mathrm{~mL}$ per mouse) for 4 (B), 8 (C), 12 (D), or 16 (E) weeks were infected with the pathogen under the same conditions. Infected mice were observed every 12 hours for 7 days to determine their survival rates. $n=12$ mice per group. ${ }^{*} P<0.05$ versus control mice using the Kaplan-Meier method. CAC, chronic alcoholconsuming; CFU, colony-forming unit; W, week.

injected intravenously into NSG mice or SCIDbgN mice that were previously decontaminated and treated with a proton-pump inhibitor. In the humanized mouse experiments, intravenously inoculated human $\mathrm{CD} 14^{+}$cells were found to spread to the major organs (spleen, lung, liver, MLNs, etc.) of the recipient mice 2 days after the cell inoculation and were persistently present for 2 weeks or more. Two days after the cell inoculation, mice were orally infected with $10^{6} \mathrm{CFU}$ of E. faecalis per mouse. In experiments for $K$. pneumoniae infection, alveolar macrophages isolated from normal and 12-week CAC mice were resuspended in PBS at a density of $1 \times 10^{7}$ cells $/ \mathrm{mL}$. Under anesthesia, a skin incision $(<1 \mathrm{~cm})$ was made, the trachea was exposed, and these cells were adoptively transferred into NSG mice by the intratracheal route $(20 \mu \mathrm{L}$ per mouse, $2 \times 10^{5}$ cells per mouse). One day later, these mice were exposed to infection with the pathogen, as described in K. Pneumoniae Pulmonary Infection.

\section{Statistical Analysis}

Data are expressed as means \pm SEM. Results were statistically analyzed by a Student's $t$-test. Survival curves were 

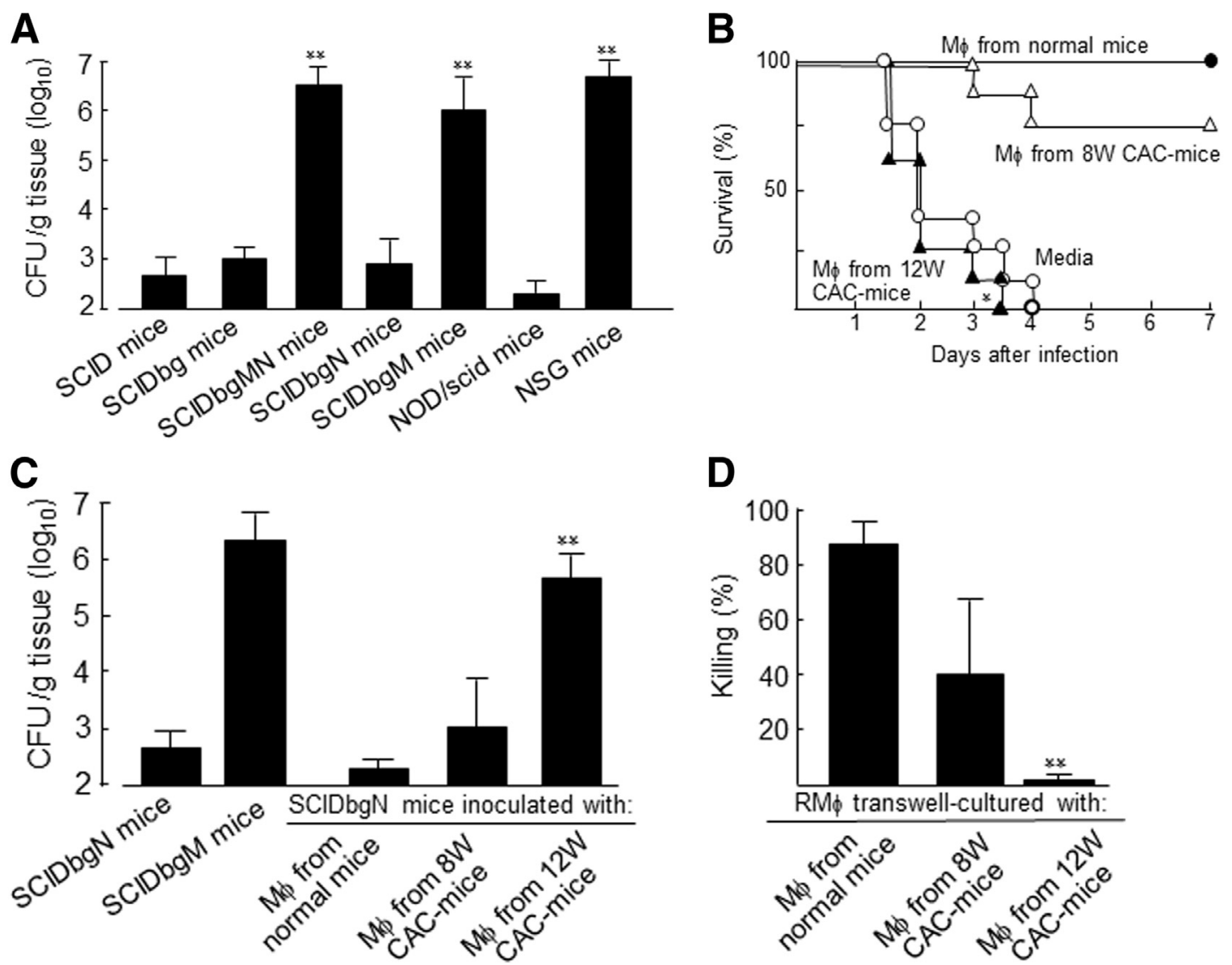

Figure 2 Macrophages are main effector cells in host resistance against sepsis that stems from $E$. faecalis translocation. A: Under decontamination and proton-pump inhibitor treatment, SCID (deficient in T and B cells), SCIDbg (deficient in T, B, and NK cells), SCIDbgMN (deficient in T, B, NK, and PMN cells and macrophages), SCIDbgN (deficient in T, B, NK, and PMN cells), SCIDbgM (deficient in T, B, and NK cells and macrophage), NOD/scid (deficient in T and B cells), and NSG (deficient in T, B, NK, and PMN cells and macrophages) mice were orally infected with E. faecalis at a dose of $10^{6}$ CFU per mouse. Translocation site tissues (MLNs), obtained from these mice 2 days after the infection, were homogenized. The number of bacteria in each organ homogenate was determined by a standard colony-counting assay. B: Under decontamination and proton-pump inhibitor treatment, NSG mice were inoculated intravenously with $5 \times 10^{6}$ cells of MLN macrophages per mouse derived from normal mice or 8W or 12W CAC mice. Two hours after cell inoculation, these mice were orally infected with E. faecalis ( $10^{6}$ CFU per mouse). Mice were observed every 12 hours for 7 days to determine their survival rates. C: The growth of E. faecalis in MLNs of SCIDbgN mice inoculated with MLN macrophages from normal mice or $8 \mathrm{~W}$ or $12 \mathrm{~W}$ CAC mice. The growth of bacteria in MLNs of these mice was determined 2 days after the oral infection. As a negative control, SCIDbgM mice were subjected to the same experiments. D: MLN macrophages $\left(1 \times 10^{6}\right.$ cells $\left./ \mathrm{mL}\right)$ from normal mice $(\mathrm{RM} \phi)$ were stimulated with $10^{6}$ heat-killed $E$. faecalis for 24 hours. Then, cells (lower chamber) were cultured in Transwell plates for an additional 24 hours with MLN macrophages (upper chamber) from normal mice or $8 \mathrm{~W}$ or $12 \mathrm{~W}$ CAC mice. After removal of the upper chamber, cells in the lower chamber were infected with $3 \times 10^{5} \mathrm{CFU}$ of $E$. faecalis per well. Three hours after incubation, the remaining bacteria in the wells were counted by a standard colony-counting assay. Data are expressed as means $\pm \operatorname{SEM}(\mathbf{A}, \mathbf{C}$ and $\mathbf{D})$ or percentage of survival (B). $n=3$ mice per group $(\mathbf{A}$ and $\mathbf{C}) ; n=8$ mice per group $(\mathbf{B})$. ${ }^{*} P<0.05$ versus NSG mice inoculated with macrophages from normal mice; ${ }^{* *} P<0.01$ versus SCID mice or SCIDbg mice (A), versus SCIDbgN mice inoculated with macrophages from normal mice (C), or versus RM $\phi$ cultured on Transwell plates with $M \phi$ from normal mice (D). CAC, chronic alcohol-consuming; CFU, colonyforming unit; M $\phi$, macrophage; MLN, mesenteric lymph node; NK, natural killer; NOD, nonobese diabetic; NSG, NOD/scid IL-2R ${ }^{\text {null; }}$ PMN, polymorphonuclear; $\mathrm{RM} \phi$, resident macrophage; SCID, severe combined immunodeficienct; SCIDbg, SCID-beige; SCIDbgM, SCID-beige mice depleted of macrophages; SCIDbgMN, SCID-beige mice depleted of macrophages and neutrophils; SCIDbgN, SCID-beige mice depleted of neutrophils; W, week.

analyzed with the Kaplan-Meier method. The result was considered significant if $P<0.05$.

\section{Results}

\section{Susceptibility of CAC Mice to Bacterial Translocation}

Under decontamination and proton-pump inhibitor treatment, normal mice and 4- to 16-week CAC mice were orally infected with $10^{6} \mathrm{CFU}$ of E. faecalis per mouse Although $100 \%$ of normal mice and 4-week CAC mice survived after infection, all of the 12 and 16-week CAC mice died within 6 days of the infection (Figure 1). Thirty percent of 8-week CAC mice died after $E$. faecalis oral infection. Sepsis from bacterial translocation was confirmed by the growth of E. faecalis in various organs and blood of 12- and 16-week CAC mice. However, growth of the pathogen in the organs of normal mice and 4-week CAC mice was not seen (data not shown). These results indicate that 12- and 16-week CAC mice are susceptible to sepsis from E. faecalis translocation, whereas normal and 4-week CAC mice are resistant.

To determine the main effector cells in host antibacterial resistance against enterococcal translocation, various groups of immunodeficient mice that were decontaminated and 
A

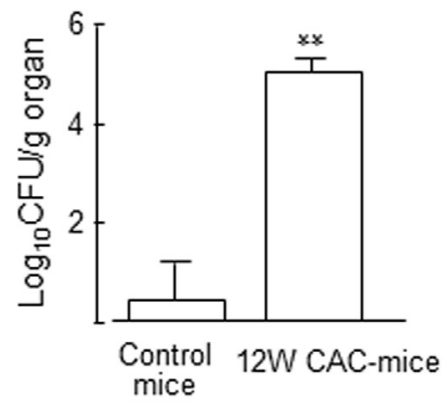

B

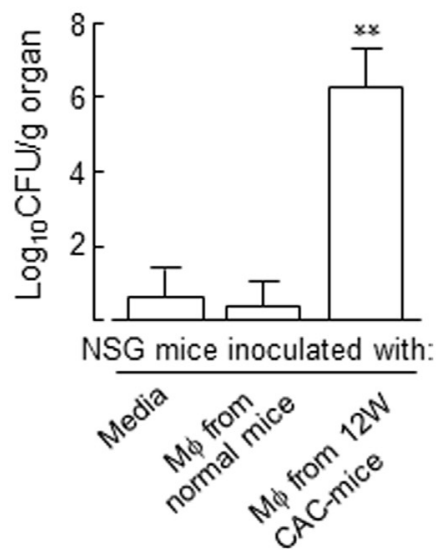

C

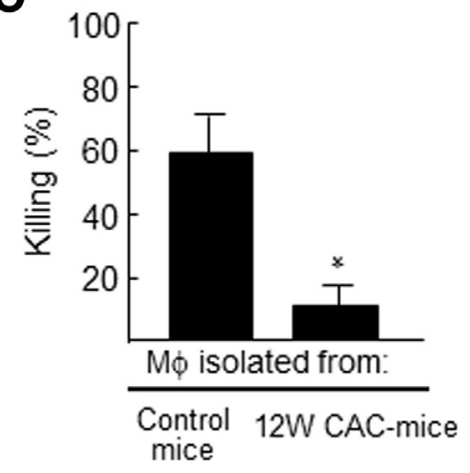

Figure 3 Susceptibility of $12 \mathrm{~W}$ CAC mice to infection with $K$. pneumoniae. A: Normal mice and $12 \mathrm{~W}$ CAC mice were infected intratracheally with $10^{3}$ CFU of K. pneumoniae per mouse. Bacterial growth in the spleen of mice infected with $K$. pneumoniae was determined by a standard colony-counting method. B: In vivo antibacterial functions of alveolar macrophages isolated from $12 \mathrm{~W}$ CAC mice. Alveolar macrophages ( $2 \times 10^{5}$ cells per mouse) isolated from normal mice or 12W CAC mice were intratracheally inoculated into NSG mice (deficient in T, B, NK, and PMN cells and macrophages). Recipient mice were then infected intratracheally with $10^{3} \mathrm{CFU}$ of $K$. pneumoniae per mouse. Bacterial growth in the spleen of recipient NSG mice infected with $K$. pneumoniae was determined by a standard colony-counting method. C: In vitro antibacterial functions of alveolar macrophages isolated from $12 \mathrm{~W}$ CAC mice. Macrophages (1 $\times 10^{6}$ cells/mL), isolated from alveolar lavages of normal mice or $12 \mathrm{~W}$ CAC mice, were stimulated with bacterial antigens ( $10^{6}$ heat-killed $\mathrm{K}$. pneumoniae) for 24 hours. Cells obtained were tested for their bactericidal activities against $K$. pneumoniae by a standard colony-counting assay. Data are expressed as means \pm SEM. $n=5$ mice per group $(\mathbf{A}) ; n=3$ independent replicates (B and $\mathbf{C}$ ). ${ }^{*} P<0.05,{ }^{*} P<0.01$ versus control mice. CAC, chronic alcohol-consuming; CFU, colony-forming unit; $M \phi$, macrophage; NK, natural killer; NSG, NOD/scid IL-2R $\gamma^{\text {null. }}$ PMN, polymorphonuclear; W, week.

treated with a proton-pump inhibitor were exposed to E. faecalis oral infection. As a result, no significant bacterial growth was seen in MLNs of SCID, SCIDbg, SCIDbgN, and NOD/scid mice after oral infection with $E$. faecalis. In contrast, after the same infection, the pathogen grew considerably in MLNs of SCIDbgMN, SCIDbgM, and NSG mice (Figure 2A). These results indicate that macrophages are the main effector cells in host antibacterial resistance against $E$. faecalis translocation.

Therefore, the antibacterial functions of translocation site (MLNs)-macrophages isolated from 12-week CAC mice were compared with that of MLN macrophages from normal and 8-week CAC mice. Thus, macrophages, isolated from MLNs of normal mice, 8-week CAC mice, and 12-week CAC mice, were adoptively transferred to NSG mice that were previously decontaminated and treated with a protonpump inhibitor. Two days after the cell inoculation, these mice were orally infected with E. faecalis. As a result, the pathogen did not kill NSG mice inoculated with MLN macrophages from normal mice (100\% survival), whereas the pathogen killed $100 \%$ of the NSG mice inoculated with 12-week CAC mouse macrophages (Figure 2B).

Next, after decontamination and proton-pump inhibitor treatment, SCIDbgN mice were adoptively transferred with MLN macrophages from normal mice, 8-week CAC mice, or 12-week CAC mice or were exposed to an oral dose of E. faecalis. SCIDbgM mice were used as a negative control. As a result, sepsis caused by E. faecalis oral infection was not developed in SCIDbgN mice and SCIDbgN mice inoculated with MLN macrophages from normal mice, whereas the pathogen spread to the entire body of
SCIDbgM and SCIDbgN mice inoculated with MLN macrophages from 12-week CAC mice (Figure 2C). These results indicate that MLN macrophages from 12-week CAC mice inhibit the macrophage-mediated host antibacterial defense of SCIDbgN mice against translocation of $E$. faecalis. In addition, the effect of 12-week CAC mouse macrophages on the bactericidal activities of resident macrophages stimulated with the antigen was examined in Transwell cultures. As a result, after cultivation in Transwell plates with 12-week CAC mouse macrophages, resident macrophages cultured with the antigen were found to be nonbactericidal, whereas the same resident macrophages cultured in Transwell plates with MLN macrophages from normal mice were found to be bactericidal (Figure 2D). These results indicate that M1 macrophage generation from resident macrophages is influenced by 12-week CAC mouse macrophages in vivo and in vitro.

\section{Susceptibility of CAC Mice to Infections with K. Pneumoniae}

The antibacterial resistance of 12-week CAC mice against K. pneumoniae was tested. This pathogen is known to be a typical opportunistic pathogen in alcoholics. As a result, a significant number of bacteria were not detected in the spleen of normal mice 2 days after $10^{3} \mathrm{CFU}$ of $\mathrm{K}$. pneumoniae per mouse by i.t. infection, whereas the pathogen was detected in the spleen of 12-week CAC mice after the same infection (Figure 3A). These results indicate that 12-week CAC mice are susceptible to pulmonary infection with $K$. pneumoniae. 


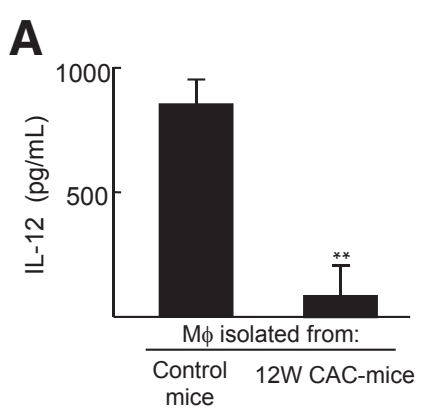

D
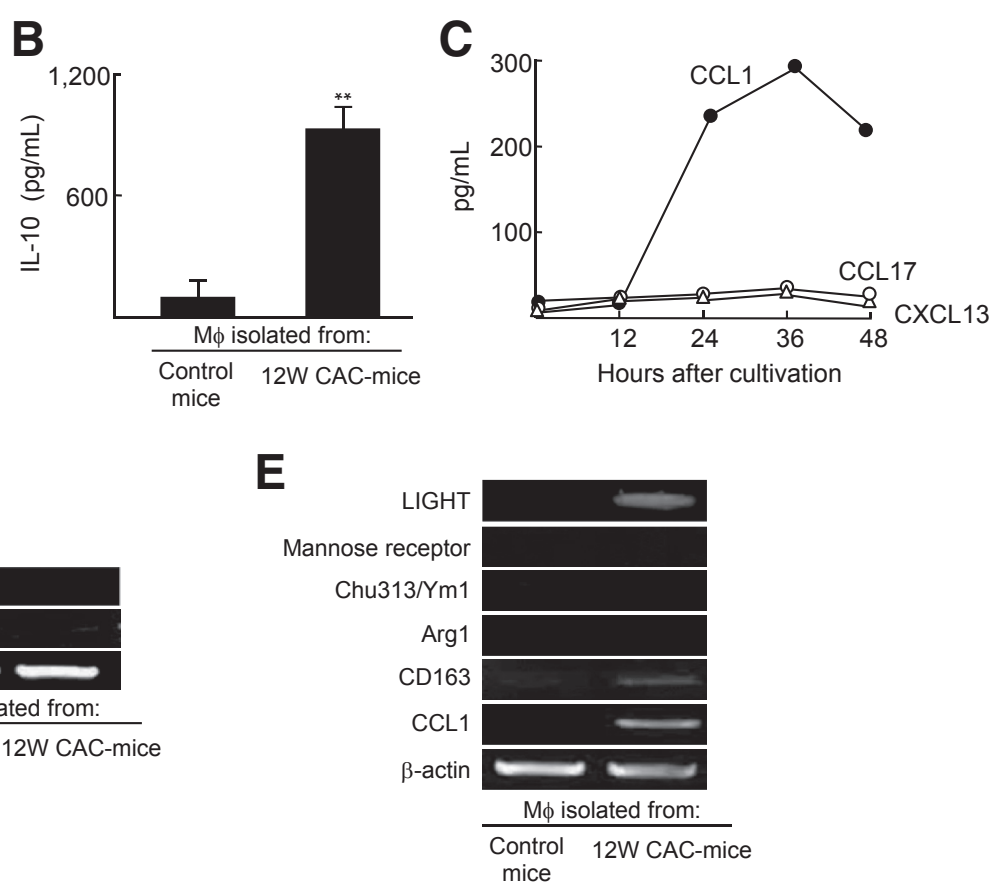

Figure 4 Properties of macrophages of 12 W CAC mice. A-C: Production of IL-12, IL-10, CCL17, CCL1, or CXCL13. MLN macrophages ( $1 \times 10^{6}$ cells $\left./ \mathrm{mL}\right)$ from normal mice or 12W CAC mice were cultured with an enterococcal antigen $\left(10^{6}\right.$ heat-killed E. faecalis) for 24 hours (IL-12 and IL-10) or 12 to 48 hours (CCL17, CCL1, and CXCL13). Culture fluids harvested were assayed for IL-12 (A), IL-10 (B), and chemokines (C) by enzyme-linked immunosorbent assay. D and E: Expression of mRNAs for various biomarkers of macrophages. MLN macrophages $\left(1 \times 10^{6}\right.$ cells $\left./ \mathrm{mL}\right)$ isolated from normal mice or $12 \mathrm{~W}$ CAC mice were stimulated with $10^{6}$ heat-killed $E$. faecalis for 24 hours. Cells obtained were analyzed for the expression of mRNAs for CXCL9, iNOS, CD163, mannose receptor, ARG1, Chu313/Ym1, and LIGHT by RT-PCR. Data are expressed as means \pm SEM of 3 different experiments $(\mathbf{A}-\mathbf{C}) . n=3$ mice in each experiment $(\mathbf{A}-\mathbf{C})$. ${ }^{* *} P<0.01$ versus control mice. CAC, chronic alcohol-consuming; CCL, chemokine ligand; iNOS, inducible nitric oxide synthase; LIGHT, homologous to lymphotoxin, exhibits inducible expression, competes with herpes simplex virus glycoprotein D for high-voltage electron microscopy on T cells; M $\phi$, macrophage; MLN, mesenteric lymph node; VEGF, vascular endothelial growth factor; W, week.

The antibacterial functions of 12-week CAC mouse macrophages were tested in vivo (NSG mice) and in vitro (bactericidal activities). The experiments were performed with alveolar macrophages isolated from normal and 12-week $\mathrm{CAC}$ mice. As a result, K. pneumoniae $\left(10^{3} \mathrm{CFU}\right.$ per mouse, intratracheally) did not grow in the spleen of NSG mice inoculated with normal mouse macrophages, whereas the pathogen did grow in the spleen of NSG mice inoculated with 12-week CAC mouse macrophages (Figure 3B). Although normal mouse macrophages killed $60 \%$ of $K$. pneumoniae, 12-week CAC mouse macrophages did not significantly kill the pathogen (Figure 3C). These results indicate that the growth of $K$. pneumoniae in NSG mice is not influenced by alveolar macrophages derived from 12-week CAC mice.

\section{Properties of 12-Week CAC Mouse Macrophages}

Twelve-week CAC mouse macrophages were biophysiologically compared with macrophages from normal mice. MLN macrophages from normal mice and 12-week CAC mice were cultured with the enterococcal antigen for 12 to 48 hours. Culture fluids harvested were assayed for IL-12, IL-10, CCL17, CCL1, and CXCL13. As a result, IL-12 was detected in culture fluids of normal mouse macrophages (Figure 4A), whereas IL-10 and CCL1 were detected in culture fluids of 12-week CAC mouse macrophages (Figure 4, B and C). CCL17 and CXCL13 were not detected in culture fluids of 12-week CAC mouse macrophages (Figure 4C). Twenty-four hours after stimulation with the enterococcal antigen, normal mouse macrophages and 12-week CAC mouse macrophages were analyzed for the expression of mRNAs for CXCL9, inducible nitric oxide synthase, CD163, mannose receptor, ARG1, Chu313/Ym1, LIGHT, and CCL1 by RT-PCR. As a result, CXCL9 and inducible nitric oxide synthase mRNAs were expressed by normal mouse macrophages stimulated with the antigen. However, these mRNAs were not expressed by 12-week CAC mouse macrophages stimulated with the antigen (Figure 4D). Under the same antigen stimulation, normal mouse MLN macrophages did not express mRNAs for CD163, mannose receptor, ARG1, Chu313/Ym1, LIGHT, and CCL1 mRNAs, whereas CD163, LIGHT, and CCL1 mRNAs were expressed by 12-week CAC mouse macrophages. In addition, mRNA expression by 12-week CAC mouse macrophages for mannose receptor, ARG1, and Chu313/ Ym1 was not stimulated by the enterococcal antigen (Figure 4E). These results indicate that MLN macrophages from 12-week CAC mice are M2b macrophages, and M2a, $\mathrm{M} 2 \mathrm{c}$, and M2d macrophages are not contained in macrophage preparations derived from 12-week CAC mice. Alveolar macrophages isolated from 12-week CAC mice were also identified as M2b macrophages (data not shown). 


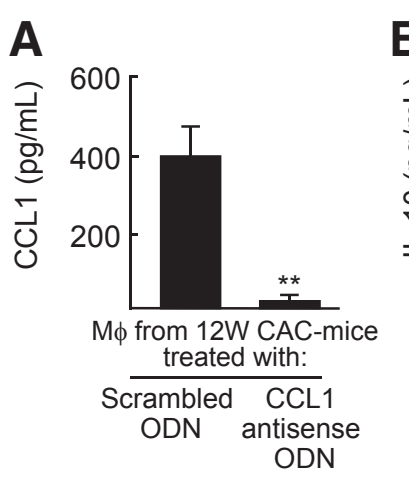

$\mathbf{E}$

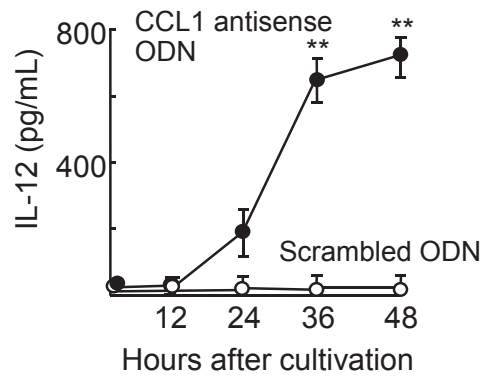

C D
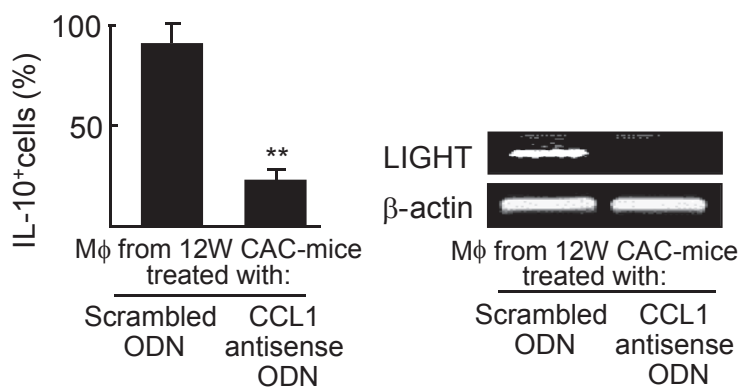

F Scrambled ODN

CCL1 antisense ODN

G
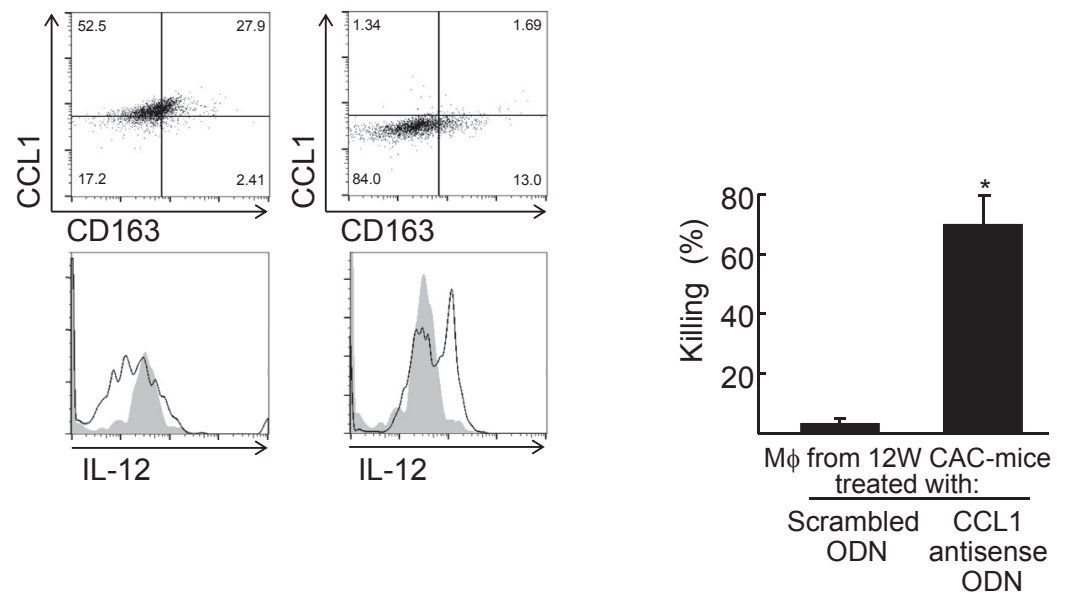

Figure 5 Properties of macrophages from 12W CAC mice treated with CCL1 antisense ODNs. A-D: Twelve-week CAC mice were treated s.C. with CCL1 antisense ODNs $\left(10 \mu \mathrm{g}\right.$ per mouse for each ODN) twice a day for 2 days. Macrophages $\left(1 \times 10^{6}\right.$ cells/mL), isolated from MLNs of $12 \mathrm{~W}$ CAC mice 1 day after the final treatment, were cultured for 24 hours without any stimulation. Culture fluids harvested were assayed for CCL1 (A) and IL-10 (B) by enzyme-linked immunosorbent assay. In addition, cells harvested were analyzed by flow cytometry (intracellular IL-10) (C) and RT-PCR (expression of LIGHT mRNA) (D). E-G: Induction of M1 macrophages by a bacterial antigen in cultures of MLN macrophages of $12 \mathrm{~W} \mathrm{CAC} \mathrm{mice} \mathrm{previously} \mathrm{treated} \mathrm{with} \mathrm{CCL1} \mathrm{antisense} \mathrm{0DNs.} \mathrm{Macrophages}\left(1 \times 10^{6}\right.$ cells/ $\mathrm{mL}$ ) from 12W CAC mice previously treated with CCL1 antisense ODNs or scrambled ODNs were cultured with heat-killed $E$. faecalis for 12 to 48 hours. Culture fluids harvested were assayed for IL-12 by enzyme-linked immunosorbent assay (E). Macrophages from 12W CAC mice previously treated with CCL1 antisense 0DNs were stimulated with heat-killed $E$. faecalis for 24 hours. Cells harvested were assayed for the expression of CD163 and intracellular IL-12 and CCL1 by flow cytometry (F) and their bactericidal activities against $E$. faecalis by a colony-counting method $(\mathbf{G})$. Data are expressed as means \pm SEM of 3 different experiments $(\mathbf{A}-\mathbf{C}$, E, and $\mathbf{G}) . n=3$ mice in each experiment $(\mathbf{A}-\mathbf{C}, \mathbf{E}$, and $\mathbf{G}) ; n=3$ independent experiments $(\mathbf{D}$ and $\mathbf{F})$. ${ }^{*} P<0.05,{ }^{*} P<0.01$ versus mice treated with scrambled ODNs. CAC, chronic alcohol-consuming; CCL, chemokine ligand; LIGHT, homologous to lymphotoxin, exhibits inducible expression, competes with herpes simplex virus glycoprotein D for high-voltage electron microscopy on T cells; M $\phi$, macrophage; MLN, mesenteric lymph node; ODN, oligodeoxynucleotide; W, week.

\section{Effect of CCL1 Antisense ODNs on the Antibacterial Resistance of 12-Week CAC Mice to Opportunistic Infections}

In our previous studies, ${ }^{48} \mathrm{M} 2 \mathrm{~b}$ macrophages derived from thermally injured mice reverted to resident macrophages after cultivation with CCL1 antisense ODNs, and the reverted macrophages from burn-associated M2b macrophages converted to M1 macrophages during cultivation with the bacterial antigen. CCL1 was characterized as an essential chemokine for the maintenance of M2b macrophage properties. ${ }^{48}$ Therefore, we attempted to revert $\mathrm{M} 2 \mathrm{~b}$ macrophages to resident macrophages in 12-week CAC mice through CCL1 antisense ODN treatment. As a result, MLN macrophages from CAC mice that were previously treated with CCL1 antisense ODNs did not produce CCL1 and IL-10 (Figure 5, A and B), did not express the intracellular IL-10 protein (Figure 5C), and did not express LIGHT mRNA (Figure 5D). IL-12 production was stimulated by the enterococcal antigen in cultures of MLN macrophages from 12-week CAC mice that were previously treated with CCL1 antisense ODNs (Figure 5E), and these macrophages were found to be $\mathrm{CD} 163^{-} \mathrm{IL}-12^{+} \mathrm{CCL1}^{-}$cells by flow cytometric analysis (Figure 5F). In addition, these macrophages displayed strong bactericidal activities against E. faecalis (Figure 5G). These results indicate that M1 macrophages with marked bactericidal activities are inducible in 12-week CAC mice exposed to the pathogen under treatment with CCL1 antisense ODNs.

In the following experiments, the protective effect of CCL1 antisense ODNs against enterococcal translocation and Klebsiella pneumonia was investigated in 12-week CAC mice. As a result, the marked growth of the pathogen was found in MLNs of 12-week CAC mice infected with E. faecalis ( $10^{6} \mathrm{CFU}$ per mouse, orally) (Figure 6A). 
A
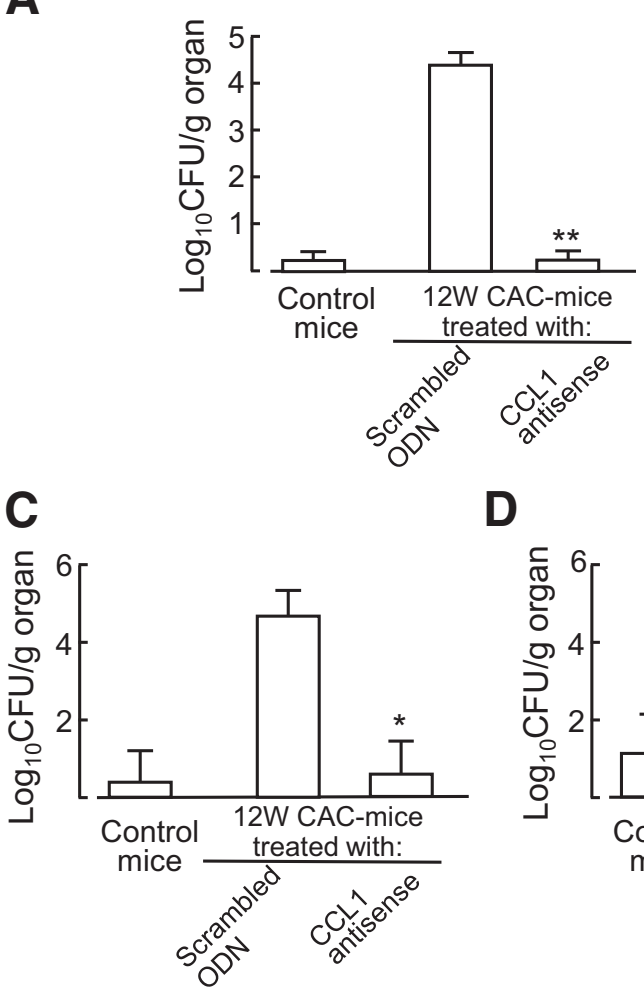

D

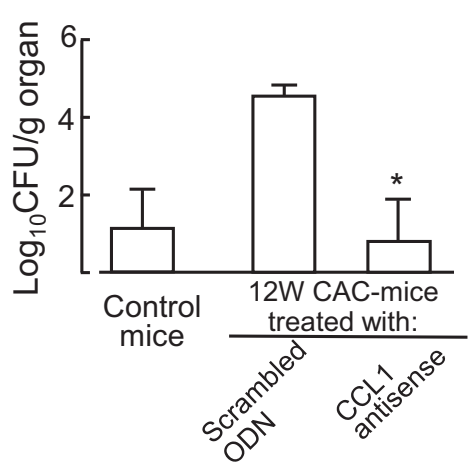

E

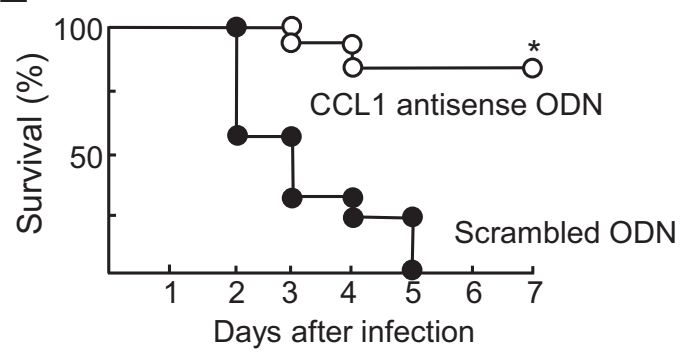

Figure 6 Resistance of 12W CAC mice treated with CCL1 antisense ODNs against infections with E. faecalis and $K$. pneumoniae. Twelve-week CAC mice were treated s.c. with CCL1 antisense ODNs (10 $\mu$ g per mouse for each ODN) twice a day for 2 days. One day after the final treatment, these mice were infected with E. faecalis (A and B; $10^{6}$ CFU per mouse, orally) or K. pneumoniae (C-E; $10^{3}$ CFU per mouse, intratracheally). Mice infected with the pathogens were observed every 12 hours for 7 days to determine their survival rates. Two days after infection, bacterial growth in MLNs (A), spleen (C), and liver (D) of these mice was determined by a standard colony-counting method. Data are expressed as means \pm SEM. $n=5$ mice (A, C, and D); $n=11-12$ mice per group (B and E). ${ }^{*} P<0.05,{ }^{* *} P<0.01$ versus mice treated with scrambled ODNs. CAC, chronic alcohol-consuming; CCL, chemokine ligand; CFU, colony-forming unit; MLN, mesenteric lymph node; ODN, oligodeoxynucleotide; W, week.

Although $100 \%$ of the 12 -week CAC mice died after infection with $10^{6} \mathrm{CFU}$ of $E$. faecalis per mouse, all of the 12-week CAC mice treated with CCL1 antisense ODNs survived after the same infections (Figure 6B). The marked growth of the pathogen was found in the spleen and liver of 12-week CAC mice infected with K. pneumoniae $\left(10^{3} \mathrm{CFU}\right.$ per mouse, intratracheally). However, these pathogens did not grow in organs of CAC mice treated with CCL1 antisense ODNs (Figure 6, C and D). Although all of the 12-week CAC mice treated with scrambled ODNs died within 5 days of $K$. pneumoniae intratracheal infection, $82 \%$ of CAC mice treated with CCL1 antisense ODNs survived after the same infection (Figure $6 \mathrm{E}$ ). These results indicate that 12 -week CAC mice treated with CCL1 antisense ODNs are resistant against lethal dose infections of certain opportunistic pathogens.

\section{Discussion}

Alcoholics are susceptible to infections that stem from microbiota in the respiratory and intestinal tracts. Commonly, pneumonia and bacterial translocation in association with microbiota do not occur in healthy hosts. Therefore, some immune dysfunctions related to alcohol abuse are considered to be the underlining reasons for the increased susceptibility of alcoholics to infections. Here, using a mouse model of chronic alcohol consumption (CAC mice), we determined how alcoholics were susceptible to opportunistic infections and tried to improve antibacterial resistance of CAC mice through the modulation of host resistance against opportunistic infections. Normal mice and 4-week CAC mice resisted infections with $E$. faecalis (bacterial translocation) and $K$. pneumoniae (pneumonia). However, 12- to 16-week CAC mice were found to be susceptible to these infections. NSG mice (immunologic empty mice) inoculated with normal mouse macrophages resisted opportunistic infections, but the same mice inoculated with 12-week CAC mouse macrophages were found to be susceptible to the infections.

Previously, ${ }^{46}$ active effector cells in host antibacterial resistance against enterococcal translocation were determined in neutrophil-depleted NSG mice with the inoculation of T cells, B cells, NK cells, macrophages, or neutrophils isolated from normal mice. In these experiments, NSG mice decontaminated and treated with a proton-pump inhibitor were orally infected with E. faecalis. As a result, the bacterial growth in MLNs was not seen in NSG mice inoculated with macrophages, but $E$. faecalis did grow in MLNs of the 
same mice inoculated with B cells, T cells, NK cells, or neutrophils. ${ }^{46}$ These studies indicate that the main effector cells in the host antibacterial resistance against bacterial translocation is the macrophage population.

Antibacterial functions of macrophages derived from normal mice and 12- to 16-week CAC mice are different. Under exposure to the bacterial antigen, properties of macrophages from 12-week CAC mice were compared with those of normal mouse macrophages. As a result, macrophages from normal mice stimulated with the antigen were found to be $\mathrm{CD} 163^{-} \mathrm{IL}-12^{+}$cells with strong bactericidal activities (M1 macrophages). Macrophages derived from 12-week CAC mice were found to be IL-10-producing and LIGHT mRNA-expressing $\mathrm{CD}_{163}{ }^{+} \mathrm{CCL} 1^{+}$macrophages (M2b macrophages). Special biomarkers of M2a, M2c, and M2d macrophages were not detected in the macrophages prepared from 12-week CAC mice. M1 macrophages were not induced by the bacterial antigen in cultures of 12-week CAC mouse macrophages, and resident macrophages stimulated with the antigen did not convert to M1 macrophages when they were cultured in Transwell plates with 12-week CAC mouse M2b macrophages.

In the subsequent studies, we tried to improve antibacterial resistance of 12-week CAC mice through the modulation of macrophage properties. In our previous studies that used burn-associated M2b macrophages, ${ }^{48} \mathrm{CCL} 1$ has been identified as an essential chemokine for the maintenance of properties for M2b macrophages, and CCL1 is produced by M2b macrophages themselves. In addition, burn-associated M2b macrophages reverted to resident macrophages in cultures depleted of CCL1. In this study, resident macrophages were isolated from 12-week CAC mice treated with CCL1 antisense ODNs, and M1 macrophages were induced by the bacterial antigen in 12-week CAC mice that were previously treated with CCL1 antisense ODNs. Furthermore, the impaired resistance of 12-week CAC mice to infections with E. faecalis and $K$. pneumoniae was improved after treatment with CCL1 antisense ODNs. These results indicate that certain opportunistic infections and subsequent sepsis are immunologically controllable in alcoholics through the modulation of M2b macrophages that appear in association with alcohol consumption, and M2b macrophages are reverted to resident macrophages in 12-week CAC mice treated with CCL1 antisense ODNs.

M2b macrophages are known to be generated from resident macrophages after combined stimulation with immune complexes (Fc receptors) and IL-1 $\beta$ (IL-1 receptor) or lipopolysaccharide (Toll-like receptor) ${ }^{49} \mathrm{~A}$ high concentration of immune complexes is seen in the circulation of alcoholics. ${ }^{50,51}$ Alcoholic hyaline derived from a consequence of destructed tissues leads to the formation of immune complexes. ${ }^{51}$ NLRP3 inflammasome activation was found in the brain and liver of mice with chronic alcohol consumption. ${ }^{52,53}$ Once NLRP3 inflammasome is activated, caspase-1 processes pro-IL-1 $\beta$ into its active form. ${ }^{54,55}$ Therefore, to test the possibility that chronic alcohol consumption causes the cleavage of pro-IL- $1 \beta$ into the mature IL- $1 \beta$, intestinal epithelial cells were isolated from 12-week CAC mice, and concentrations of pro-IL-1 $\beta$ (inactive) and mature IL- $1 \beta$ (active) in epithelial cell lysates were measured with enzymelinked immunosorbent assay kits. Pro-IL-1 $\beta$ amounts in epithelial cell lysates of 12-week CAC mice and normal mice stimulated with pathogens were not significantly different; however, mature IL-1 $\beta$ amounts in the cell lysates from 12week CAC mice were increased compared with those in normal mice (Supplemental Figure S1). These results indicate that NLRP3 inflammasome activation (a source of IL-1 $\beta$ ) is strongly influenced by chronic alcohol consumption, and M2b macrophages are, at least in part, generated from resident macrophages stimulated with IL-1 $\beta$ and immune complexes distributed throughout the body. In addition, the cellular activation of $\mathrm{Fc}$ receptor was found in alveolar and spleen macrophages of ethanol-fed rats. ${ }^{56}$ Alcohol consumption-associated activation of Fc receptor may also be involved in the generation of M2b macrophages in 12-week CAC mice. Further studies are needed to determine the mechanism of $\mathrm{M} 2 \mathrm{~b}$ macrophage predomination in alcoholics.

It was reported that M2 macrophages play an important role in controlling hepatocellular injuries (excessive or prolonged inflammation in liver) in ethanol-fed mice. ${ }^{57-60}$ M1 macrophages were detected in injured liver tissues (inflammation sites) of these mice. ${ }^{57-59} \mathrm{M} 1$ macrophages were eliminated from the injured area through the induction of M2 macrophages, and hepatocellular injuries of ethanolfed mice were improved. ${ }^{60}$ These facts suggest that the elimination of M2b macrophages may cause the acceleration of hepatocellular injuries developed in alcoholics. Further studies are required to determine a pathogenic role of M1 macrophages and M2 macrophages in alcoholics.

\section{Supplemental Data}

Supplemental material for this article can be found at http://dx.doi.org/10.1016/j.ajpath.2014.09.022.

\section{References}

1. Naimi TS, Brewer RD, Mokdad A, Denny C, Serdula MK, Marks JS: Binge drinking among US adults. JAMA 2003, 289:70-75

2. Moss M: Epidemiology of sepsis: race, sex, and chronic alcohol abuse. Clin Infect Dis 2005, 41(Suppl 7):S490-S497

3. Zhang P, Bagby GJ, Happel KI, Raasch CE, Nelson S: Alcohol abuse, immunosuppression, and pulmonary infection. Curr Drug Abuse Rev 2008, 1:56-67

4. Engelich G, Wright DG, Hartshornm KL: Acquired disorders of phagocyte function complicating medical and surgical illnesses. Clin Infect Dis 2001, 33:2040-2048

5. Bhatty M, Pruett SB, Swiatlo E, Nanduri B: Alcohol abuse and Streptococcus pneumoniae infections: consideration of virulence factors and impaired immune responses. Alcohol 2011, 45:523-539

6. Fernández-Solá J, Junqué A, Estruch R, Monforte R, Torres A, Urbano-Márquez A: High alcohol intake as a risk and prognostic factor for community-acquired pneumonia. Arch Intern Med 1995, 155:1649-1654 
7. Szabo G, Mandrekar P: A recent perspective on alcohol, immunity, and host defense. Alcohol Clin Exp Res 2009, 33:220-232

8. Weisfelt M, de Gans J, van der Ende A, van de Beek D: Communityacquired bacterial meningitis in alcoholic patients. PLoS One 2010, 5: e9102

9. Bode C, Bode JC: Effect of alcohol consumption on the gut. Best Pract Res Clin Gastroenterol 2003, 17:575-592

10. Tabata T, Tani T, Endo Y, Hanasawa K: Bacterial translocation and peptidoglycan translocation by acute ethanol administration. J Gastroenterol 2002, 37:726-731

11. Kim YG, Udayanga KG, Totsuka N, Weinberg JB, Núñez G, Shibuya A: Gut dysbiosis promotes M2 macrophage polarization and allergic airway inflammation via fungi-induced ${ }_{2}$. Cell Host Microbe 2014, 15:95-102

12. Szabo G: Consequences of alcohol consumption on host defence. Alcohol Alcohol 1999, 34:830-841

13. Siggins RW, Melvan JN, Welsh DA, Bagby GJ, Nelson S, Zhang P: Alcohol suppresses the granulopoietic response to pulmonary Streptococcus pneumoniae infection with enhancement of STAT3 signaling. J Immunol 2011, 186:4306-4313

14. Bagby GJ, Zhang P, Stoltz DA, Nelson S: Suppression of the granulocyte colony-stimulating factor response to Escherichia coli challenge by alcohol intoxication. Alcohol Clin Exp Res 1998, 22: $1740-1745$

15. Mørland H, Johnsen J, Bjørneboe A, Bjørneboe GE, Drevon CA, Mørland J, Mørland B: Reduced IgG Fc-receptor-mediated phagocytosis in human monocytes isolated from alcoholics. Alcohol Clin Exp Res 1988, 12:755-759

16. Bautista AP: Chronic alcohol intoxication primes Kupffer cells and endothelial cells for enhanced CC-chemokine production and concomitantly suppresses phagocytosis and chemotaxis. Front Biosci 2002, 7:a117-a125

17. Boé DM, Richens TR, Horstmann SA, Burnham EL, Janssen WJ, Henson PM, Moss M, Vandivier RW: Acute and chronic alcohol exposure impair the phagocytosis of apoptotic cells and enhance the pulmonary inflammatory response. Alcohol Clin Exp Res 2010, 34: $1723-1732$

18. Pascual M, Fernández-Lizarbe S, Guerri C: Role of TLR4 in ethanol effects on innate and adaptive immune responses in peritoneal macrophages. Immunol Cell Biol 2011, 89:716-727

19. Zisman DA, Strieter RM, Kunkel SL, Tsai WC, Wilkowski JM, Bucknell KA, Standiford TJ: Ethanol feeding impairs innate immunity and alters the expression of Th1- and Th2-phenotype cytokines in murine Klebsiella pneumonia. Alcohol Clin Exp Res 1998, 22: $621-627$

20. Domínguez-Santalla MJ, Vidal C, Viñuela J, Pérez LF, GonzálezQuintela A: Increased serum IgE in alcoholics: relationship with Th1/Th2 cytokine production by stimulated blood mononuclear cells. Alcohol Clin Exp Res 2001, 25:1198-1205

21. Liu W, Li J, Tian W, Xu T, Zhang Z: Chronic alcohol consumption induces cardiac remodeling in mice from Th1 or Th2 background. Exp Mol Pathol 2011, 91:761-767

22. Laso FJ, Vaquero JM, Almeida J, Marcos M, Orfao A: Chronic alcohol consumption is associated with changes in the distribution, immunophenotype, and the inflammatory cytokine secretion profile of circulating dendritic cells. Alcohol Clin Exp Res 2007, 31: $846-854$

23. Pan HN, Sun R, Jaruga B, Hong F, Kim WH, Gao B: Chronic ethanol consumption inhibits hepatic natural killer cell activity and accelerates murine cytomegalovirus-induced hepatitis. Alcohol Clin Exp Res 2006, 30:1615-1623

24. Laso FJ, Lapeña P, Madruga JI, SanMiguel JF, Orfao A, Iglesias MC, Alvarez-Mon M: Alterations in tumor necrosis factor-alpha, interferon-gamma, and interleukin- 6 production by natural killer cellenriched peripheral blood mononuclear cells in chronic alcoholism: relationship with liver disease and ethanol intake. Alcohol Clin Exp Res 1997, 21:1226-1231
25. Starkenburg S, Munroe ME, Waltenbaugh C: Early alteration in leukocyte populations and Th1/Th2 function in ethanol-consuming mice. Alcohol Clin Exp Res 2001, 25:1221-1230

26. Shellito JE, quan Zheng M, Ye P, Ruan S, Shean MK, Kolls J: Effect of alcohol consumption on host release of interleukin-17 during pulmonary infection with Klebsiella pneumoniae. Alcohol Clin Exp Res 2001, 25:872-881

27. Latif O, Peterson JD, Waltenbaugh C: Alcohol-mediated polarization of type 1 and type 2 immune responses. Front Biosci 2002, 7 : a135-a147

28. Medzhitov R, Janeway CA Jr: Innate immunity: impact on the adaptive immune response. Curr Opin Immunol 1997, 9:4-9

29. Sester DP, Stacey KJ, Sweet MJ, Beasley SJ, Cronau SL, Hume DL: The actions of bacterial DNA on murine macrophages. J Leukoc Biol 1999, 66:542-548

30. Rothfuchs AG, Gigliotti D, Palmblad K, Andersson U, Wigzell H, Rottenberg ME: IFN- $\alpha / \beta$-dependent, IFN- $\gamma$ secretion by bone marrowderived macrophages controls an intracellular bacterial infection. J Immunol 2001, 167:6453-6461

31. Rosenberger CM, Finlay BB: Phagocyte sabotage: disruption of macrophage signalling by bacterial pathogens. Nat Rev Mol Cell Biol $2003,4: 385-396$

32. Tanaka H, Miyazaki S, Sumiyama Y, Kakiuchi Y: Role of macrophages in a mouse model of postoperative MRSA enteritis. J Surg Res 2004, 118:114-121

33. Tsuda Y, Shigematsu K, Kobayashi M, Herndon DN, Suzuki F: Role of polymorphonuclear neutrophils on infectious complications stemming from Enterococcus faecalis oral infection in thermally injured mice. J Immunol 2008, 180:4133-4138

34. Katakura T, Yoshida T, Kobayashi M, Herndon DN, Suzuki F: Immunological control of methicillin-resistant Staphylococcus aureus (MRSA) infection in an immunodeficient murine model of thermal injuries. Clin Exp Immunol 2005, 142:419-425

35. Katakura T, Miyazaki M, Kobayashi M, Herndon DN, Suzuki F: CCL17 and IL-10 as effectors that enable alternatively activated macrophages to inhibit the generation of classically activated macrophages. J Immunol 2004, 172:1407-1413

36. Mantovani A, Sica A, Sozzani S, Allavena P, Vecchi A, Locati M: The chemokine system in diverse forms of macrophage activation and polarization. Trends Immunol 2004, 25:677-686

37. Edwards JP, Zhang X, Frauwirth KA, Mosser DM: Biochemical and functional characterization of three activated macrophage populations. J Leukoc Biol 2006, 80:1298-1307

38. Ferrante CJ, Leibovich SJ: Regulation of macrophage polarization and wound healing. Adv Wound Care (New Rochelle) 2012, 1:10-16

39. Wang Q, Ni H, Lan L, Wei X, Xiang R, Wang Y: Fra-1 protooncogene regulates IL- 6 expression in macrophages and promotes the generation of M2d macrophages. Cell Res 2010, 20:701-712

40. Tsuda Y, Takahashi H, Kobayashi M, Hanafusa T, Herndon DN, Suzuki F: Three different neutrophil subsets exhibited in mice with different susceptibilities to infection by methicillin-resistant Staphylococcus aureus. Immunity 2004, 21:215-226

41. Hardonk MJ, Dijkhuis FW, Hulstaert CE, Koudstaal J: Heterogeneity of rat liver and spleen macrophages in gadolinium chloride-induced elimination and repopulation. J Leukoc Biol 1992, 52:296-302

42. Piganelli JD, Martin T, Haskins K: Splenic macrophages from the NOD mouse are defective in the ability to present antigen. Diabetes 1998, 47:1212-1218

43. O'Brien BA, Huang Y, Geng X, Dutz JP, Finegood DT: Phagocytosis of apoptotic cells by macrophages from NOD mice is reduced. Diabetes 2002, 51:2481-2488

44. Marée AF, Komba M, Finegood DT, Edelstein-Keshet L: A quantitative comparison of rates of phagocytosis and digestion of apoptotic cells by macrophages from normal (BALB/c) and diabetes-prone (NOD) mice. J Appl Physiol (1985) 2008, 104:157-169

45. Takenaka K, Prasolava TK, Wang JC, Mortin-Toth SM, Khalouei S, Gan OI, Dick JE, Danska JS: Polymorphism in Sirpa modulates 
engraftment of human hematopoietic stem cells. Nat Immunol 2007, 8:1313-1323

46. Kobayashi M, Nakamura K, Cornforth M, Suzuki F: Role of M2b macrophages in the acceleration of bacterial translocation and subsequent sepsis in mice exposed to whole body ${ }^{137} \mathrm{Cs} \gamma$-irradiation. J Immunol 2012, 189:296-303

47. Shigematsu K, Asai A, Kobayashi M, Herndon DN, Suzuki F: Enterococcus faecalis translocation in mice with severe burn injury: a pathogenic role of CCL2 and alternatively activated macrophages (M2aM $\phi$ and M2cM $\phi)$. J Leukoc Biol 2009, 86: 999-1005

48. Asai A, Nakamura K, Kobayashi M, Herndon DN, Suzuki F: CCL1 released from $\mathrm{M} 2 \mathrm{~b}$ macrophages is essentially required for the maintenance of their properties. J Leukoc Biol 2012, 92:859-867

49. Martinez FO, Sica A, Mantovani A, Locati M: Macrophage activation and polarization. Front Biosci 2008, 13:453-461

50. Thomas HC, De Villiers D, Potter B, Hodgson H, Jain S, Jewell DP, Sherlock S: Immune complexes in acute and chronic liver disease. Clin Exp Immunol 1978, 31:150-157

51. Penner E, Albini B, Milgrom F: Detection of circulating immune complexes in alcoholic liver disease. Clin Exp Immunol 1978, 34: $28-31$

52. Lippai D, Bala S, Petrasek J, Csak T, Levin I, Kurt-Jones EA, Szabo G: Alcohol-induced $\mathrm{IL}-1 \beta$ in the brain is mediated by NLRP3/ASC inflammasome activation that amplifies neuroinflammation. J Leukoc Biol 2013, 94:171-182
53. von Moltke J, Ayres JS, Kofoed EM, Chavarría-Smith J, Vance RE: Recognition of bacteria by inflammasomes. Annu Rev Immunol 2013, 31:73-106

54. Bergsbaken T, Fink SL, Cookson BT: Pyroptosis: host cell death and inflammation. Nat Rev Microbiol 2009, 7:99-109

55. Latz E, Xiao TS, Stutz A: Activation and regulation of the inflammasomes. Nat Rev Immunol 2013, 13:397-411

56. Bagasra O, Howeedy A, Kajdacsy-Balla A: Macrophage function in chronic experimental alcoholism. I. Modulation of surface receptors and phagocytosis. Immunology 1988, 65:405-409

57. Wan J, Benkdane M, Teixeira-Clerc F, Bonnafous S, Louvet A, Lafdi F, Pecker F, Tran A, Gual P, Mallat A, Lotersztajn S, Pavoine C: M2 Kupffer cells promote M1 Kupffer cell apoptosis: a protective mechanism against alcoholic and nonalcoholic fatty liver disease. Hepatology 2014, 59:130-142

58. Louvet A, Teixeira-Clerc F, Chobert MN, Deveaux V, Pavoine C, Zimmer A, Pecker F, Mallat A, Lotersztajn S: Cannabinoid CB2 receptors protect against alcoholic liver disease by regulating Kupffer cell polarization in mice. Hepatology 2011, 54:1217-1226

59. Mandal P, Pratt BT, Barnes M, McMullen MR, Nagy LE: Molecular mechanism for adiponectin-dependent M2 macrophage polarization: link between the metabolic and innate immune activity of full-length adiponectin. J Biol Chem 2011, 286:13460-13469

60. Curtis BJ, Zahs A, Kovacs EJ: Epigenetic targets for reversing immune defects caused by alcohol exposure. Alcohol Res 2013, 35: 97-113 